\title{
Predictors of central vestibular compensation after surgery for vestibular schwannomas
}

\author{
Fattori predittivi di compensazione vestibolare centrale dopo chirurgia \\ per lo schwannoma vestibolare
}

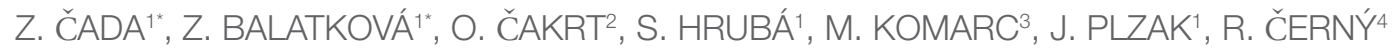 \\ ${ }^{1}$ Department of Otorhinolaryngology and Head and Neck Surgery, $1^{1 \text { st }}$ Faculty of Medicine Charles University in Prague \\ and Motol University Hospital, Postgraduate Medical School; ${ }^{2}$ Department of Rehabilitation and Sports Medicine, \\ $2^{\text {nd }}$ Faculty of Medicine, Charles University in Prague and Motol University Hospital, Postgraduate Medical School; \\ ${ }^{3}$ Department of Anthropomotorics and Methodology, Faculty of Physical Education and Sport, Charles University in \\ Prague; ${ }^{4}$ Department of Neurology, $2^{\text {nd }}$ Faculty of Medicine, Charles University in Prague and Motol University Hospital, \\ Postgraduate Medical School \\ * These authors contributed equally to this work.
}

\begin{abstract}
SUMMARY
Surgical removal of vestibular schwannoma causes acute vestibular symptoms, including postoperative vertigo which is the most negative factor affecting quality of life in patients after vestibular schwannoma surgery. The main aim of this study is to determine whether the results from routine electronystagmography with pathological visually-provoked responses can predict poor postoperative compensation. We also investigate whether postoperative central compensation is related to objective parameters such age, tumour size, length of surgery and persistent nystagmus. According to the results from preoperative electronystagmography, patients were divided into three groups: peripheral, central and combined vestibular syndrome. Signs of central compensation were evaluated by the presence of postoperative nystagmus, vertigo, deviation of subjective visual vertical and head impulse test. There were no statistically significant differences between groups in observed signs of compensation. These results suggest that pathological central oculomotor parameters are not a negative predictive factor for central vestibular compensation.
\end{abstract}

KEY WORDS: Vestibular function • Central compensation • Electronystagmography • Vertigo

\section{RIASSUNTO}

La rimozione chirurgica dello schwannoma vestibolare è causa di sintomi vestibolari acuti, inclusa la vertigine postoperatoria che rappresenta il fattore che influenza più negativamente la qualità della vita dei pazienti dopo questo tipo di chirurgia. Scopo principale di questo studio è stato quello di determinare se i risultati dell' elettronistagmografia con risposte provocate patologiche possano prevedere una scarsa compensazione postoperatoria. Abbiamo inoltre ricercato se la compensazione postoperatoria possa essere correlata con parametri oggettivi come l'età, le dimensioni del tumore, la durata della chirurgia e la persistenza del nistagmo. Sulla base dei risultati dell' elettronistagmografia preoperatoria, i pazienti sono stati divisi in tre gruppi: con sindrome vestibolare periferica, centrale o combinata. I segni di compensazione centrale sono stati valutati dalla presenza di nistagmo postoperatorio, vertigine, deviazione della verticale soggettiva ed "head impulse" test. Non vi sono state differenze statisticamente significative fra i due gruppi nei segni di compensazione osservati. Questi risultati suggeriscono che i parametri oculomotori centrali patologici non sono un fattore predittivo negativo per la compensazione vestibolare centrale.

PAROLE CHIAVE: Funzione vestibolare $\bullet$ Compensazione centrale $\bullet$ Elettronistagmografia $\bullet$ Vertigini

\section{Introduction}

Surgery for vestibular schwannoma leads to acute vestibular dysfunction in the postoperative period ${ }^{12}$. Surgery leads to acute vestibular syndrome due to vestibular asymmetry.

After each acute vestibular asymmetry, central compensation initiates but usually subsides over weeks to months. After surgery, patients compensate with variability in vertigo symptoms, but such variability is still poorly un- derstood. With advancing age, internal and neurologic comorbidities slow down the process of compensation. Central compensation depends on functional integrity of central vestibular and cerebellar centres ${ }^{3}$. Older patients or those with additional central nervous disorders may have a problem with vestibular compensation that can be prolonged or even inadequate ${ }^{34}$. Patients with uncompensated unilateral vestibular loss typically suffer from chronic vertigo, instability, postural imbalance and per- 
sistent spontaneous nystagmus. Patients with vestibular schwannomas may have impaired balance due to direct vestibular nerve compression or pressure on the brain stem and cerebellum.

According to the type of functional impairment, patients with vestibular schwannoma can be divided into three groups with a peripheral, central, or mixed (combined) vestibular syndrome pattern.

The primary endpoint of the study is smooth pursuit movements and/or optokinetic and saccadic responses in predicting poor compensation following vestibular schwannoma surgery.

Secondary end-points include correlation of compensation markers with age, gender, tumour size, duration of surgery and persistence of nystagmus.

\section{Materials and methods}

In this study, 47 patients (28 males and 19 females; mean age, 46 years; range, 19-74 years) who underwent surgery for vestibular schwannomas (retrosigmoid approach) between 2009 and 2010 were included. All patients were examined pre-operatively by neurologists, ENT specialists and an ophthalmologist, and determined to be candidates for surgery. Most patients had profound hearing loss on the tumour side (pure tone average $>55 \mathrm{~dB}$ ). Five patients had mild hearing loss on the tumour side. The size of the tumour was classified according to the Koos classification (Table I). All patients were pre-operatively evaluated by neuro-otologists. A history of vertigo was documented in all patients before surgery. The examination included evaluation for spontaneous nystagmus, and testing of the vestibulo-ocular reflex by head impulse testing and subjective visual vertical examination. All patients were evaluated pre-operatively by electronystagmography. Electronystagmography was performed using a four-channel electronystagmograph (Toennies Nystagliner, Wuerzburg, Germany). Electronystagmographic examination (ENG) included examination of spontaneous nystagmus with and without fixation, gaze direction nystagmus, smooth pursuit test, examination of saccades, recording of optokinetic nystagmus, and rotational and caloric tests. Based on the results of the ENG battery, patients were classified into the following three categories: peripheral vestibular syndrome; central vestibular syndrome; and combined vestibular syndrome (Table II).

Central vestibular syndrome was defined as abnormal results in tests for smooth pursuit movements (SPEMs), abnormal saccades and optokinetic response. Vestibuloocular reflex gain, as examined by rotational and caloric tests, were within normal limits and no asymmetry was present. Central oculomotoric movements in the vertical plane are not routinely evaluated in our laboratory.

SPEM were considered abnormal when saccades intrusion and/or a staircase appearance was noted. The limits of norm of SPEM gain are shown in Table III.

Saccades abnormalities are defined as hypermetria or hypometria. The limits of norms are shown in Table II.

Table I. Characteristics of patients.

\begin{tabular}{|c|c|c|c|c|c|}
\hline Patients & Total & Peripheral syndrome & Central syndrome & Combined syndrome & $P$ value \\
\hline Number of patients (\%) & $47(100.0)$ & $18(38.3)$ & $19(40.4)$ & $10(21.3)$ & \\
\hline Side of tumour/left (number, \%) & $27(57.4)$ & $9(50.0)$ & $11(57.9)$ & $7(70.0)$ & 0.590 \\
\hline Age/years (mean, SD) & $46.1(13.9)$ & $45.1(12.3)$ & $48.1(13.6)$ & $44.4(17.9)$ & 0.741 \\
\hline Length of surgery/hours (mean, SD) & $8.2(2.1)$ & $7.3(1.9)$ & $8.7(2.5)$ & $8.8(0.6)$ & 0.073 \\
\hline $\begin{array}{l}\text { Vertigo (mean, SD) } \\
\text { - } \text { preoperatively } 0 \text { (number, \%) } \\
\text { - preoperatively } 1 \text { (number, \%) } \\
\text { - preoperatively } 2 \text { (number, \%) }\end{array}$ & $\begin{array}{c}0.4(0.5) \\
26(55.3) \\
21(44.7) \\
0(0.0)\end{array}$ & $\begin{array}{c}0.3(0.5) \\
12(66.7) \\
6(33.3) \\
0(0.0)\end{array}$ & $\begin{array}{c}0.4(0.5) \\
11(57.9) \\
8(42.1) \\
0(0.0)\end{array}$ & $\begin{array}{l}0.7(0.5) \\
3(30.0) \\
7(70.0) \\
0(0.0)\end{array}$ & $\begin{array}{l}0.175 \\
- \\
- \\
-\end{array}$ \\
\hline $\begin{array}{l}\text { Spontaneous nystagmus } \\
\text { - preoperatively (number, \%) } \\
\text { - postoperatively (number, \%) }\end{array}$ & $\begin{array}{c}- \\
0(0.0) \\
26(55.3)\end{array}$ & $\begin{array}{c}- \\
0(0.0) \\
11(61.1)\end{array}$ & $\begin{array}{c}- \\
0(0.0) \\
8(42.1)\end{array}$ & $\begin{array}{c}- \\
0(0.0) \\
7(70.0)\end{array}$ & $\begin{array}{c}- \\
- \\
0.293\end{array}$ \\
\hline $\begin{array}{l}\text { SW } \\
\text { - preoperatively (mean, SD) } \\
\text { - postoperatively (mean, SD) } \\
\text { - } 3 \text { months after surgery (mean, SD) }\end{array}$ & $\begin{array}{c}- \\
0.0(0.0) \\
2.1(3.6) \\
0.8(1.6)\end{array}$ & $\begin{array}{c}- \\
0.0(0.0) \\
2.33(2.74) \\
1.22(1.83)\end{array}$ & $\begin{array}{c}- \\
0.0(0.0) \\
2.26(4.83) \\
0.68(1.7)\end{array}$ & $\begin{array}{c}- \\
0.0(0.0) \\
1.4(2.32) \\
0.2(0.63)\end{array}$ & $\begin{array}{c}- \\
- \\
0.791 \\
0.263\end{array}$ \\
\hline $\begin{array}{l}\text { Tumour stage (mean, SD) } \\
\text { - stage I (number, \%) } \\
\text { - stage II (number, \%) } \\
\text { - stage III (number, \%) } \\
\text { - stage IV (number, \%) }\end{array}$ & $\begin{array}{l}3.5(0.9) \\
2(4.3) \\
7(14.9) \\
6(12.8) \\
32(68.1)\end{array}$ & $\begin{array}{l}2.9(1.1) \\
2(11.1) \\
5(27.8) \\
3(16.7) \\
8(44.4)\end{array}$ & $\begin{array}{c}3.7(0.7) \\
0(0.0) \\
2(10.5) \\
1(5.3) \\
16(84.2)\end{array}$ & $\begin{array}{l}3.8(0.4) \\
0(0.0) \\
0(0.0) \\
2(20.0) \\
8(80.0)\end{array}$ & $\begin{array}{l}0.008 \\
- \\
- \\
- \\
-\end{array}$ \\
\hline
\end{tabular}

SD: standard deviation; SW: subjective visual vertical. 
Table II. Characteristics of vestibular syndromes.

\begin{tabular}{lcccccc} 
& SpN & OKN & SPEM & Saccades & Rotational test & Caloric test \\
Central & -+ & + & + & + & - & - \\
Peripheral & + & - & - & - & + & + \\
Mixed & + & + & + & + & + & + \\
\hline
\end{tabular}

SpN: spontaneous nystagmus; OKN: optokinetic nystagmus; SPEM: pursuit smooth movements; +: abnormal result; -: normal result; - +: abnormality is not obl.

Optokinetic nystagmus was classified as abnormal when nystagmus beats were absent or irregular or dysrhythmic. The quantitative parameters of abnormalities are presented in Table II.

The criteria for peripheral vestibular hypofunction were caloric or rotational hyporeflexia, positive head impulse testing and absence of the above-mentioned central oculomotor abnormalities ${ }^{5-7}$.

Combined (mixed) vestibular syndrome was defined as the combination of pathologies in central and peripheral parameters.

The clinical examination included a search for nystagmus and corrective sacades in head impulse testing, stand and gait stability and subjective visual vertical. Two subjective scales were used (vertigo intensity and validated questionnaire [Dizziness Handicap Inventory $\{\mathrm{DHI}\}])$. Vertigo intensity was assessed by subjective numerical rating scale in three degrees ( 0,1 and 2). Vertigo 0 indicates very slight instability without nausea or emesis. Vertigo 1 indicates instability provoked by fast movements of the head and/or body with slight nauzea and no emesis. Vertigo 2 means that patients have rotatory vertigo, poor stability, and nausea with possible emesis.

Patients were examined before surgery (Time 1) and shortly (2 to 4 days after surgery) after surgery (Time 2), and then at 3 weeks (Time 3 ) and 3 months after surgery (Time 4).

In all patients, both vestibular nerves (superior and inferior) were macroscopically resected together with the tumour using a retrosigmoid-transmeatal approach. All patients were postoperatively instructed to practice a vestibular training programme adopted for patients with acute vestibular loss ${ }^{8}$. The programme included gaze stability exercises, smooth pursuit and saccadic eye move- ments, and postural exercises to improve balance control and gait stability.

\section{Questionnaires}

The DHI contains 25 items with a score from 0 to +100 , with a higher score indicating more severe handicap.

\section{Statistical analysis}

Data are expressed as the mean $\pm \mathrm{SD}$, or summarised as absolute frequencies and percentages as appropriate. Differences between groups of patients with different types of vestibular syndrome (peripheral, central, and combined) were evaluated by one-way analysis of variance (ANOVA). A chi-square test was used to compare count variables. Changes in vertigo perception and DHI in patients with different types of vestibular syndrome were tested using two-way repeated ANOVA (time x group), followed by a series of LSD post-hoc tests. The Spearman correlation coefficient was calculated to express the magnitude of the relationship between particular variables. A two-tailed $\mathrm{p}$ value $<0.05$ was considered statistically significant. Statistical analyses were performed using IBM SPSS (version 22; IBM SPSS, Armonk, NY, USA).

\section{Results}

During the study period, 50 patients underwent surgery for vestibular schwannomas using a retrosigmoid-transmeatal approach. Three patients were excluded from the study because they declined inclusion for various reasons.

The tumour was situated on the left side in 27 patients (57.4\%); 21(44.7\%) patients had pre-operative dizziness. In 7 patients $(14.9 \%)$ cerebrospinal fluid leaks were observed from spinal fluid pseudocysts. All cysts were con-

Table III. Limits of norms for ENG tests, $95 \% \mathrm{Cl}$.

\begin{tabular}{|c|c|c|c|c|c|}
\hline $\begin{array}{l}\text { SPEM }\left(0.29^{\circ} / \mathrm{s}\right) \\
\text { gain }\end{array}$ & $\begin{array}{l}\text { OKN }\left(36^{\circ} / \mathrm{s}\right) \\
\text { gain }\end{array}$ & $\begin{array}{c}\text { OKN } \\
\text { maximum velocity } \\
(\% / \mathrm{s})\end{array}$ & $\begin{array}{c}\text { Saccade } \\
\text { dissymmetry } \\
(\%)\end{array}$ & $\begin{array}{c}\text { Saccade } \\
\text { latency }(\mathrm{ms})\end{array}$ & $\begin{array}{l}\text { Sinusoidal } \\
\text { rotation test } \\
\text { gain }\end{array}$ \\
\hline $0.65-1.07$ & $0.52-1.15$ & $19-42$ & $\begin{array}{l}\text { Right eye right saccade } 88-108 \\
\text { Left eye right saccade } 89-110 \\
\text { Right eye left saccade } 89-111 \\
\text { Left eye left saccade } 88-108\end{array}$ & $129-255$ & $0.24-0.85$ \\
\hline
\end{tabular}


servatively treated by puncture and compression during the first postoperative week.

No patients had pre-operative spontaneous nystagmus and abnormal deviation of subjective visual vertical. Most of tumours were stage IV (32 patients [68.1\%]). Six patients (12.8\%) had stage III tumours, 7 patients (14.9\%) had stage II tumours, and 2 patients $(4.3 \%)$ had stage I tumours (Table I).

According to the results of ENG, patients were divided into three categories (peripheral, central and combined). Eighteen patients $(38.3 \%)$ had peripheral vestibular syndrome, 19 patients (40.4\%) had central vestibular syndrome and 10 patients $(21.3 \%)$ had combined vestibular syndrome.

These three groups (peripheral, combined and central) did not differ with respect to age, presence of pre- and postoperative spontaneous nystagmus, sensation of vertigo, or deviation of subjective visual vertical ( $p>0.05)$. Statistically significant differences were observed $(p<0.05)$ between size of tumour and type of syndrome, in which patients with large tumours had more central signs on ENG $(\mathrm{p}<0.05$; Table I). All patients had vertigo with nausea shortly after surgery.

Patients with central and peripheral pre-operative findings had post-operative non-significant reduction of vertigo in comparison with the preoperative level. At 3 weeks and 3 months post-operatively the vertigo sensation in these groups was non-significantly worse (Fig. 1, Table IV). A significant difference was observed $(\mathrm{p}<0.05)$ in patients with combined findings who had smaller vertigo intensity at 3 weeks post-operatively compared with the pre-operative state (Fig. 1, Table IV).

These results were in contrast to the DHI results. There was a significant $(\mathrm{p}<0.05)$ increase in the DHI score at 3 months post-operatively in the peripheral and central groups (Fig. 2, Table IV). In the combined group, there was also an increase in DHI scores, but statistical significance was not reached $(\mathrm{p}=0.056)$.

Other factors studied, such as age, side of the tumour and length of surgery did not influence the compensation (Table I).

\section{Discussion}

Resection of vestibular schwannomas is a good model of acute unilateral peripheral vestibular asymmetry. An episode of acute vestibular asymmetry leads to central compensation, which persists for approximately several weeks ${ }^{9}$.

A central oculomotor pathology can be found, especially in patients with cerebellar dysfunction ${ }^{410}$. In this study, 29 patients $(61.7 \%)$ had central abnormalities, which is higher than other reports ${ }^{1211}$, because most tumours were stages 3 or 4 , which we assume represented cerebellar compression.

The primary aim of this study was to determine whether or not central pathological oculomotor findings measured

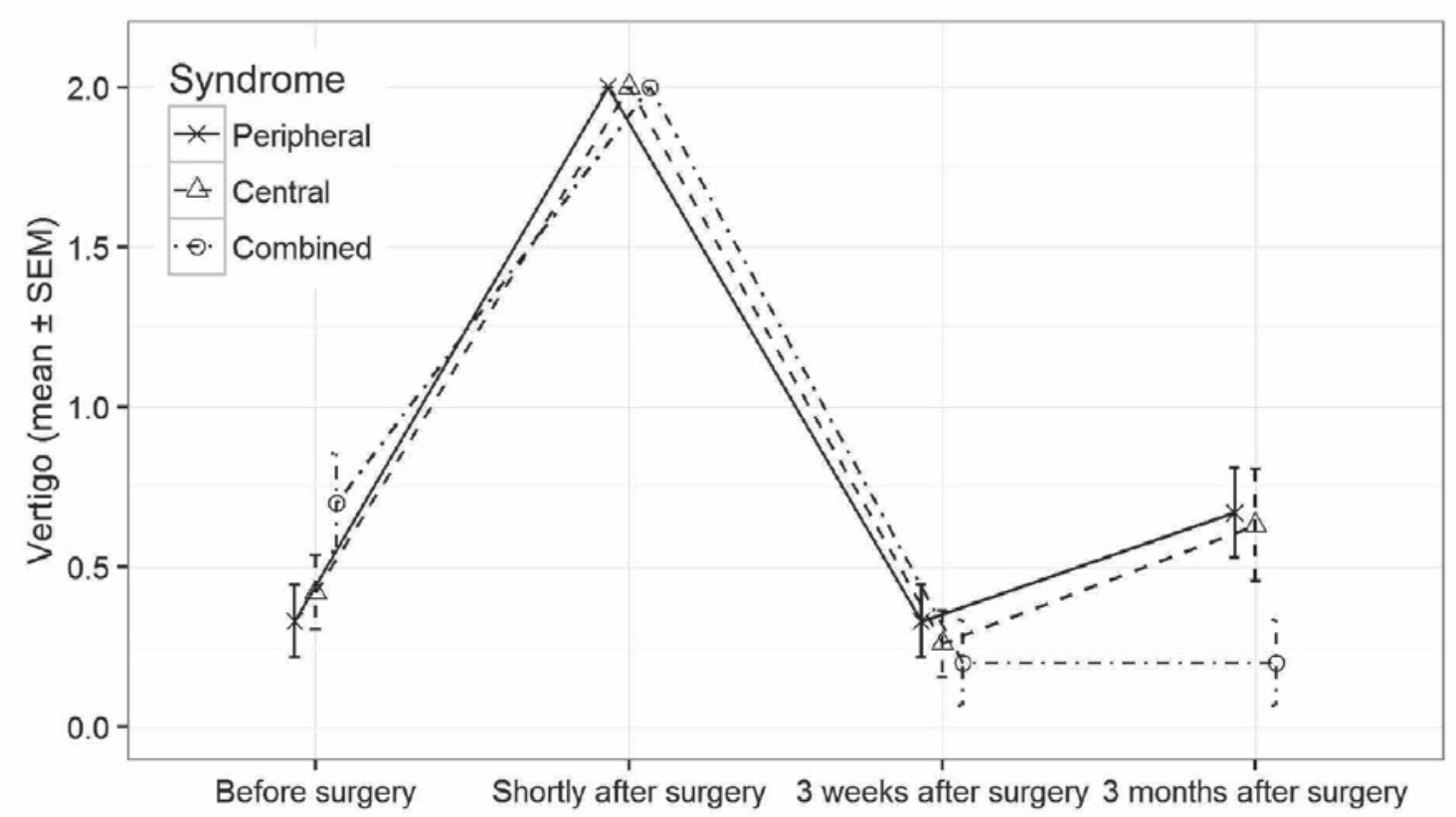

SEM: standard error of the mean.

Fig. 1. Changes in vertigo mean values ( \pm standard error of the mean) in patients with different syndromes. 
Table IV. Outcome parameters according to group.

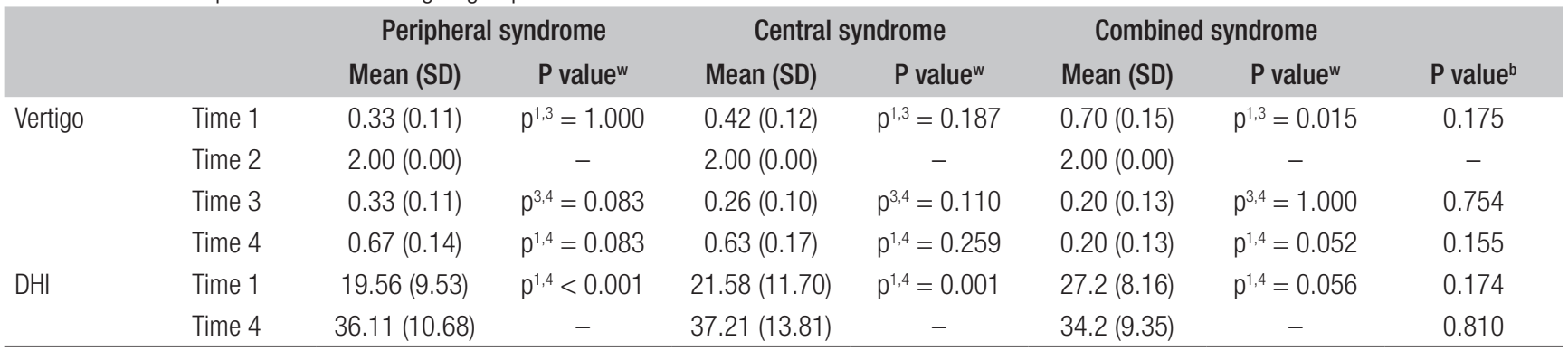

SD: standard deviation; $p$-valuew: within-group differences tested by LSD post-hoc tests after repeated measures ANOVA; Time 1: before surgery; Time 2: shortly after surgery; Time 3: 3 weeks after surgery; Time 4: 3 months after surgery; $p^{1,3}: p$-value of the difference between Time 1 and Time 3; $p^{1,4}: p$-value of the difference between Time 1 and Time 4; $p^{2,4}$ : $p$-value of the difference between Time 2 and Time 4; $p^{3,4}$ : $p$-value of the difference between Time 3 and Time 4; $p$-value: between-group differences tested by one-way ANOVA.

pre-operatively by ENG (pursuit smooth movements, saccadic system and optokinetic system) are negative predictive factors for post-operative central compensation.

Post-operative central compensation was evaluated subjectively by questionnaires assessing sensation of vertigo and objectively by the presence of spontaneous pre- and post-operative nystagmus and subjective visual vertical. With respect to the presence of spontaneous nystagmus and abnormal deviation of subjective visual vertical (SVV) at 3 weeks and 3 months after surgery, our study did not find a significant difference between patients with central parameters pre-operatively. These results are in agreement with other studies ${ }^{411}$.
We also attempted to determine whether or not the total DHI score and the vertigo intensity scale differed between patients with and without central signs. There were no significant differences between groups in DHI scores pre-operatively and 3 months postoperatively, and the same was true for the vertigo intensity questionnaire pre-operatively at 3 weeks and 3 months postoperatively. This result differs from a report in which central signs affected DHI scoring ${ }^{11}$. Our results are in line with that of the larger group of schwannoma patients in whom DHI deteriorated from preoperative values to higher scores at three months after surgery. The scores remained practically stable at 12-month follow-

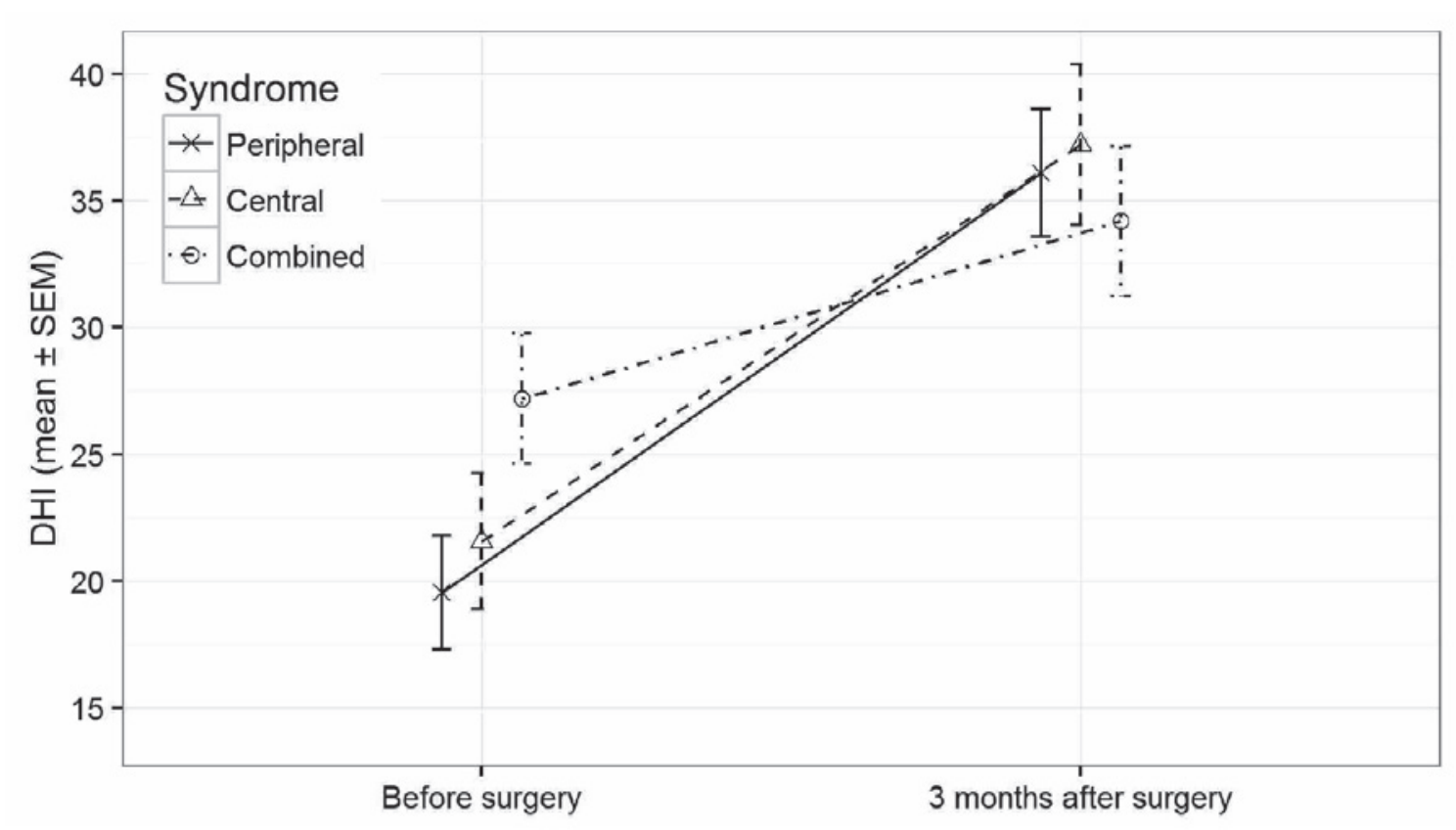

SEM: standard error of the mean.

Fig. 2. DHI mean values ( \pm standard error of the mean) before surgery and 3 months after surgery in patients with different syndromes. 
up postoperatively. There was a trend to higher scores with larger tumour size ${ }^{12}$.

Patients with central signs had decreased sensations of vertigo at 3 weeks after surgery compared with preoperative sensations. In the combined group, the difference was statistically significant $(\mathrm{p}<0.05)$. Three months post-operatively, the sensation of vertigo in the central and peripheral group was non-significantly worse than at 3 weeks postoperatively. In patients with combined syndrome, the sensation of vertigo at 3 weeks and 3 months post-operatively remained unchanged.

Combined vestibular syndrome has significantly low vertigo intensity in comparison to the other two groups at three months. DHI score of the combined group is lower than the score of peripheral and central groups, even if this was not statistically significant. This fact, as theoretically the most affected (combined) group has the best outcome, is not easy to explain. As combined syndrome subjects exhibited a higher DHI score in the pre-operative period, it is possible that they are better adapted to the chronic handicap and do not deteriorate further.

Significant findings were observed in all groups for DHI scoring pre-operatively and at 3 months post-operatively. This result suggests that the DHI questionnaire is more applicable for monitoring vestibular function in real life and the sensation of vertigo as an isolated symptom of one aspect of vestibular function is not sufficient for follow-up of subjective compensation in daily life.

Contrary to our expectations, we found that abnormal results of the oculomotor tests in the pre-operative period do not predict less favourable outcomes at 3 months postoperatively.

Specifically, there was no correlation between vertigo intensity and DHI scoring and SPEM, OKN and saccades performance. We have analysed this topic from several viewpoints; specifically, the entire ENG record was summarised and classified into three distinct groups (normal, central, peripheral, or mixed type abnormalities). There was no difference between these groups in terms of both vertigo intensity and DHI score at the 3-month follow-up evaluation. When analysing the subgroup with high DHI scores (unfavourable outcome), no significant accumulation of central type abnormities was found. There is little correlation between symptoms traditionally considered as important for central vestibular compensation and the real clinical outcome at 3 months post-neurectomy.

Vestibular compensation is a complex process based on changes in all levels of integration of vestibular afference. It cannot be constrained only to vestibular nuclei and archicerebellum. Participation of the posterior insular, superior temporal and parietal cortex on vestibular compensa- tion was shown by voxel-based morphometry in the study of Helmchen et al. ${ }^{13}$.

The exact site of affection in the central vestibular structures by the high grade vestibular schwannoma can differ substantially between cases, which can explain the variable clinical presentations observed in our study. It seems that detailed brainstem imaging would be necessary to explain why oculomotor abnormalities are observed in some high-grade schwannoma and absent in others with seemingly similar radiological presentation. Specifically, signs of flocculo-nodular lobe, olivo-cerebellar tracts, dorsolateral pontine nuclei and vermis should correlate with oculomotor tests more closely. This explanation would appear to be supported by similar studies ${ }^{14}{ }^{15}$. In a study on cerebellopontine angle meningioma, cerebellar signs were observed in only $32 \%$ of cases, depending on the anatomical circumstances ${ }^{16}$. In the study by Berrettini, best diagnostic sensitivity was achieved by combination of ENG and brain stem auditory evoked potentials ${ }^{17}$.

On the other hand, oculomotor abnormalities documented by ENG examination are highly specific and failure in these circuits does not interfere with the vestibular compensation, as shown by this study. This result is supported by the large study of Stipkovits, who did not find a consistent correlation between tumour size and level of compensation ${ }^{18}$.

The main result of this study is the evidence that routine oculomotor tests in vestibular functional laboratory are poor predictors of the overall outcome following vestibular schwannoma surgery. There is a need for other factors to be implemented in presurgical evaluation with possibly better prediction capability. We speculate that the level of presurgical compensation of vestibular deficit is an important factor for final functional outcomes. This factor should be investigated with a higher level of detail using video head impulse test, vestibular evoked potentials, gain at high and low frequency rotatory stimulation and functional measures of postural stability. We also suggest that tests of overall fitness, factors affecting quality of life and personal traits should be included in future studies.

We see the main weakness of the study in the fact that routine preoperative imaging cannot identify the anatomical details needed for evaluation of central vestibular structures involvement by the pathological process.

\section{Conclusions}

Pre-operatively measured signs of central pathology have little impact on the process of vestibular compensation in acute complete unilateral vestibular lesions.

The results of this study can be clinically used in patients 
with combined vestibular pathology (e.g. intractable Meniere disease after brain stroke) in which surgery is indicated, but central signs, which are usually present in patients after brain stroke, represent a contraindication to the surgery ${ }^{19}$. Compensation of vestibular loss is a complex process that includes central recalibration of vestibular reactivity and oculomotor functions, changes in postural strategy and important individually variable psychological factors ${ }^{20}$. From these, only oculomotor and vestibular responses can be evaluated by ENG examination. Clearly, important parts are missing. Future analyses should take into account parameters of postural stability, psychological factors and measures of quality of life. These functional factors probably have a higher influence on overall vestibular compensation than formal measures of vestibular function in the ENG laboratory.

From a practical standpoint, the results of the ENG battery should be considered with care. In particular, abnormal results of oculomotor subtests do not predict a poor efficacy of vestibular rehabilitation or a final functional outcome.

\section{Acknowledgements}

Supported by PROGRES Q28, UNCE 204013, GAUK 310216, and the Ministry of Health of the Czech Republic (grant No. 15-28933A).

\section{Conflict of interest statement}

None declared.

\section{References}

1 Vidal PP, de Waele C, Vibert N, et al. Vestibular compensation revisited. Otolaryngol Head Neck Surg 1998;119:34-42.

2 Barbara M, Ronchetti F, Manni V, et al. Double localization of a unilateral sporadic vestibular schwannoma. Acta Otorhinolaryngol Ital 2008;28:34-7.

3 Herdman SJ, Clendaniel RA, Mattox DE, et al. Vestibular adaptation exercises and recovery:acute stage after acoustic neuroma resection. Otolaryngology - Head And Neck Surgery 1995;113:77-87.

4 Furman JM, Balaban CD, Pollack IF. Vestibular compensation in a patient with a cerebellar infarction. Neurology 1997;48:916-20.
5 Szirmai A, Keller B. Electronystagmographic analysis of caloric test parameters in vestibular disorders. Eur Arch Otorhinolaryngol 2013;270:87-91.

6 Van Der Stappen A, Floris LW, Van De Heyning PH. Computerized electronystagmography:normative data revisited. Acta Otolaryngol 2000;120:724-30.

7 Jacobson GP, Newman CW, Kartush JM. Handbook of balance function testing. Mosby; 1992. p. 360.

8 Hirvonen M, Aalt H, Hirvonen TP. Postural control after vestibular schwannoma resection measured with visual feedback posturography. ORL J Otorhinolaryngol Relat Spec 2005;67:335-9.

9 Cohen HS, Kimball KT, Jenkins HA. Factors affecting recovery after acoustic neuroma resection. Acta Oto-Laryngologica 2002;122:841-50.

10 Čada Z, Balatková Z, Chovanec M, et al. Vertigo perception and quality of life in patients after surgical treatment of vestibular schwannoma with pretreatment prehabituation by chemical vestibular ablation. Biomed Res Int 2016;2016:6767216.

11 Thomeer H, Bonnard D, Franco-Vidal V, et al. Prognostic factors of balance quality after transpetrosal vestibular schwannoma microsurgery: an instrumentally and DHI-based prospective cohort study of 48 patients. Otol Neurotol 2015;36:886-91.

12 Humphriss RL, Baguley DM, Moffat DA. Change in dizziness handicap after vestibular schwannoma excision. Otol Neurotol 2003;24:661-5.

13 Helmchen C, Klinkenstein JC, Krüger A, et al. Structural brain changes following peripheral vestibulo-cochlear lesion may indicate multisensory compensation. J Neurol Neurosurg Psychiatry 2011;82:309-16.

14 Mohamed ES. Predictors of central vestibular disorders from videonystagmography tests. Egypt J Otolaryngol 2016;32:202-9.

15 Kumar A, Mafee M, Torok N. Anatomic specificity of central vestibular signs in posterior fossa lesions. Ann Otol Rhinol Laryngol 1982;91:510-5.

16 Voss NF, Vrionis FD, Heilman CB, et al. Meningiomas of the cerebellopontine angle. Surg Neurol 2000;53:439-46.

17 Berrettini S, Ravecca F, Sellari-Franceschini S, et al. Acoustic neuroma: correlations between morphology and otoneurological manifestations. J Neurol Sci 1996;144:24-33.

18 Stipkovits EM, Van Dijk JE, Graamans K. Electronystagmographic changes in patients with unilateral vestibular schwannomas in relation to tumor progression and central compensation. Eur Arch Otorhinolaryngol 1999;256:173-6.

19 Göksu N, Bayazit YA, Yilmaz M, et al. Surgical treatment of peripheral vertigo and vertiginous diseases. ORL J Otorhinolaryngol Relat Spec 2005;67:1-9.

20 Peusner KD, Shao M, Reddaway R, et al. Basic concepts in understanding recovery of function in vestibular reflex networks during vestibular compensation. Front Neurol 2012;3:17.

Received: December 18, 2017 - Accepted: February 22, 2018

How to cite this article: Čada Z, Balatková Z, Čakrt O, et al. Predictors of central vestibular compensation after surgery for vestibular schwannomas. Acta Otorhinolaryngol Ital 2019;39:46-52. https://doi.org/10.14639/0392-100X-1963

Address for correspondence: Jan Plzák, Department of Otorhinolaryngology and Head and Neck Surgery, $1^{\text {st }}$ Faculty of Medicine, Charles University in Prague, Faculty Hospital Motol, Postgraduate Medical School, v. Úvalu, 84, 15006 Praha, Czech Republic. Tel. +420 224434301. E-mail: jan.plzak@fnmotol.cz 